\title{
Influence of High-Pressure Nitrogenation on the Structure, Magnetism and Microwave Absorption Properties of $\mathrm{SmFe}_{10} \mathrm{Mo}_{2}$
}

\author{
Nai-Kun Sun $\cdot$ Jie Guo $\cdot$ Sheng-Jie Du $\cdot$ Song-Ning Xu $\cdot$ Ping-Zhan Si $\cdot$ Jin-Jun Liu
}

Received: 20 November 2014/Revised: 30 January 2015/Published online: 22 March 2015

(C) The Chinese Society for Metals and Springer-Verlag Berlin Heidelberg 2015

\begin{abstract}
Nitrogenation of $\mathrm{SmFe}_{10} \mathrm{Mo}_{2}$ powders was performed in a self-made furnace under a high-purity $\mathrm{N}_{2}$ atmosphere up to $40 \mathrm{MPa}$ at $500{ }^{\circ} \mathrm{C}$. Upon nitrogenation at atmospheric pressure, the lattice parameters $a$ and $c$ increase by $0.5 \%$ and $2.7 \%$, respectively, whereas the Curie temperature $T_{\mathrm{C}}$ increases from 519 to $633 \mathrm{~K}$. With further increasing the nitrogenation pressure to 20 and $40 \mathrm{MPa}$, the 1:12 main phase starts to decompose and a large amount of Mo and $\alpha-\mathrm{Fe}$ precipitates. This leads to variation of Mo concentration in the 1:12 phase and causes a sharp decrease in $T_{\mathrm{C}}$ and in the coercivity. The relative complex permittivity and permeability of paraffin-SmFe ${ }_{10} \mathrm{Mo}_{2}$ composites show multi-resonant behavior. After nitrogenation, the magnetic loss of the powders decreases, which may originate from the influence of eddy currents due to the increase in the particle size.
\end{abstract}

KEY WORDS: High-pressure nitrogenation; $\mathrm{SmFe}_{10} \mathrm{Mo}_{2}$-based compounds; Curie temperature; Microwave absorption

\section{Introduction}

The intrinsic magnetic properties, especially the anisotropy, of $\mathrm{R}_{12} \mathrm{Fe}_{17}$ and $\mathrm{R}(\mathrm{Fe}, M)_{12}$ (named 1:12 phase) intermetallics, with $M=\mathrm{Ti}, \mathrm{V}, \mathrm{Cr}, \mathrm{Mn}, \mathrm{Mo}, \mathrm{Al}, \mathrm{W}$ and $\mathrm{Si}$, have been found to improve dramatically upon introduction of interstitial nitrogen hydrogen or carbon which increases the unit cell volume, narrows the $3 \mathrm{~d}$-electron band and modifies the

Available online at http://link.springer.com/journal/40195

N.-K. Sun $(\bowtie) \cdot$ J. Guo $\cdot$ S.-J. Du · S.-N. Xu

School of Science, Shenyang Ligong University, Shenyang 110159, China

e-mail: naikunsun@163.com

P.-Z. Si

College of Materials Science and Engineering, China Jiliang University, Hangzhou 310018, China

\section{J.-J. Liu}

Faculty of Materials Science and Chemical Engineering, Ningbo University, Ningbo 315211, China crystal-field interaction [1-4]. After nitrogenation, the R(Fe, Mo) ${ }_{12}$ compounds with the $\mathrm{ThMn}_{12}$ structure show an increased Curie temperature, a larger saturation magnetization and a stronger uniaxial magnetocrystalline anisotropy. The compounds $\mathrm{Nd}(\mathrm{Fe}, \mathrm{Mo}){ }_{12} \mathrm{~N}_{x}[5]$ and $\operatorname{Pr}(\mathrm{Fe}, \mathrm{Mo}){ }_{12} \mathrm{~N}_{x}[6]$ have been demonstrated to be suitable as new hard magnetic materials with high coercivity of up to $6.2 \mathrm{kOe}\left(4.94 \times 10^{5}\right.$ $\mathrm{A} / \mathrm{m}$ ) and maximum energy products of up to $12.0 \mathrm{MGOe}$ $\left(95.52 \mathrm{~kJ} / \mathrm{m}^{3}\right)$. So far, only few studies have been focused on the Sm nitrides with the $\mathrm{ThMn}_{12}$ structure. The Rietveld analysis of the XRD patterns for $\mathrm{SmFe}_{10} \mathrm{Mo}_{2} \mathrm{~N}_{x}$ shows that the $\mathrm{N}$ atoms occupy exclusively the $2 \mathrm{~b}$ interstitial site [7]. Most of the nitrogenation has been carried out at atmospheric pressure or even lower pressure. Therefore, it is meaningful to investigate the influence of high-pressure nitrogenation on the structure and magnetism of the $\mathrm{ThMn}_{12}$-type compounds. In the present study, nitrogenation of the $\mathrm{SmFe}_{10} \mathrm{Mo}_{2}$ powders was carried out in a self-made furnace under a high-purity $\mathrm{N}_{2}$ atmosphere of up to $40 \mathrm{MPa}$ and the influence of high-pressure nitrogenation on the structure and magnetism has been studied. 
Based on soft ferromagnetic metals, the composites such as $(\mathrm{Fe}, \mathrm{Ni}) / \mathrm{C}[8]$ and $\mathrm{Ni} / \mathrm{Al}_{2} \mathrm{O}_{3}$ [9] show excellent electromagnetic wave absorption properties mainly due to a high saturation magnetization and a high Snoek limit. Recent research has shown that the microstructure and concentration of the ferromagnetic and dielectric components have large effect on the microwave-absorption properties $[10$, 11]. Low-frequency dielectric studies on core-shell composite fibers of the magnesium ferrite-polyvinylidene fluoride indicate that the addition of the magnesium ferrite increases the polarization which results in an increase in the dielectric constant but decreases the dielectric loss [12]. Both the dielectric resonance and magnetic resonance are closely related to the size of the metal grains in $\mathrm{Ni} / \mathrm{TiO}_{2}$ [13] and $\mathrm{Fe} / \mathrm{TiO}_{2}[14]$ nanocomposites produced by milling and annealing. So far, few studies have focused on the microwave absorption properties of the composites based on permanent magnet materials. Recently, it has been reported that a large reflection loss (RL) from 9.6 to $18 \mathrm{GHz}$ exceeding $-10 \mathrm{~dB}$ is achieved in $\mathrm{Nd}_{2} \mathrm{Fe}_{14} \mathrm{~B} / \mathrm{C}$ microparticles for an absorber thickness of 1.4-2.6 mm [15]. In the present study, microwave-absorption properties of $\mathrm{SmFe}_{10} \mathrm{Mo}_{2}$ nanoparticles and the influence of nitrogenation have been investigated.

\section{Experimental}

The parent compound $\mathrm{SmFe}_{10} \mathrm{Mo}_{2}$ was synthesized by arc melting from $99.9 \%$ pure starting materials and annealed in vacuum at $950{ }^{\circ} \mathrm{C}$ for 2 weeks. The annealed bulk sample was pulverized by mechanical alloying for $2 \mathrm{~h}$ using a high-energy ball-milling machine with a rotational speed of $300 \mathrm{r} / \mathrm{min}$ and nitrogenated at $500{ }^{\circ} \mathrm{C}$ in a self-made furnace in a high-purity $\mathrm{N}_{2}$ atmosphere at pressures up to $40 \mathrm{MPa}$. The as-prepared bulk alloy was denoted as sample $\mathrm{A}$, and the ball-milled powder and the samples nitrogenized at $0.1,20$ and $40 \mathrm{MPa}$ were named as sample B, C, D and $\mathrm{E}$, respectively.

$\mathrm{X}$-ray diffraction (XRD) was performed using $\mathrm{Cu} K_{\alpha}$ radiation by a Rigaku $d / \mathrm{Max}-\gamma \mathrm{A}$ diffractometer. The magnetic properties were measured in a vibrating sample magnetometer (Lakeshore 7407) at applied magnetic fields up to $1.8 \mathrm{~T}$ at the temperature range from 300 to $750 \mathrm{~K}$. The toroidal specimens for measurement of the electromagnetic wave absorption properties between 2 and $18 \mathrm{GHz}$ by means of a Agilent 8722ES network analyzer were prepared by uniformly mixing $40 \mathrm{wt} \% \mathrm{SmFe}_{10} \mathrm{Mo}_{2}$ particles or $\mathrm{SmFe}_{10} \mathrm{Mo}_{2}$ nitride particles with $60 \mathrm{wt} \%$ paraffin. The morphology and size distribution of the particles and the energy dispersive spectrum (EDS) were examined by means of a Hitachi-3400 N scanning electron microscope (SEM).

\section{Results and Discussion}

3.1 Influence of High-Pressure Nitrogenation on the Structure and Magnetism of $\mathrm{SmFe}_{10} \mathrm{Mo}_{2}$

Figure 1 shows the XRD patterns of the bulk $\mathrm{SmFe}_{10} \mathrm{Mo}_{2}$, the powder and the nitrides. The bulk sample has the tetragonal $\mathrm{ThMn}_{12}$-type structure with a small amount of $\alpha$ $\mathrm{Fe}$ as impurity phase. For the powder sample milled for $2 \mathrm{~h}$, a large amount of Mo is found which was precipitated from the 1:12 phase. Nitrogenation at $0.1 \mathrm{MPa}$ does not change the 1:12 phase structure and only causes a shift of the reflections to lower angles, indicating the lattice expansion. With further increasing the nitrogenation pressure to 20 and $40 \mathrm{MPa}$, the 1:12 main phase starts to decompose and large amounts of Mo and $\alpha-\mathrm{Fe}$ were precipitated. Previously, it has been observed that upon substitution of $\mathrm{Ti}$ (with smaller radius) for $\mathrm{V}$ in $\mathrm{NdFe}_{10.5} \mathrm{~V}_{1.5} \mathrm{~N}_{y}$, the $1: 12$ main phase starts to decompose and $\alpha$-Fe precipitates [16]. The measured lattice parameters $a$ and $c$ of the 1:12 main phase are listed in Table 1. It is worthwhile noting that upon nitrogenation, the lattice parameters $a$ and $c$ of the asmilled powder have increased by $0.5 \%$ and $2.7 \%$, respectively. With further increasing pressure to 20 and $40 \mathrm{MPa}$, the lattice parameters exhibit a slight increase, indicating gradual saturation of the nitrogenation.

Figure 2 shows the SEM images EDS spectra of the samples nitrogenized at 0.1 and $40 \mathrm{MPa}$. It can be clearly seen from Fig. 2a, c that there is a quite large size distribution of the particles of the two samples. For sample C, the particle size varies roughly from $8 \mu \mathrm{m}$ to $100 \mathrm{~nm}$,

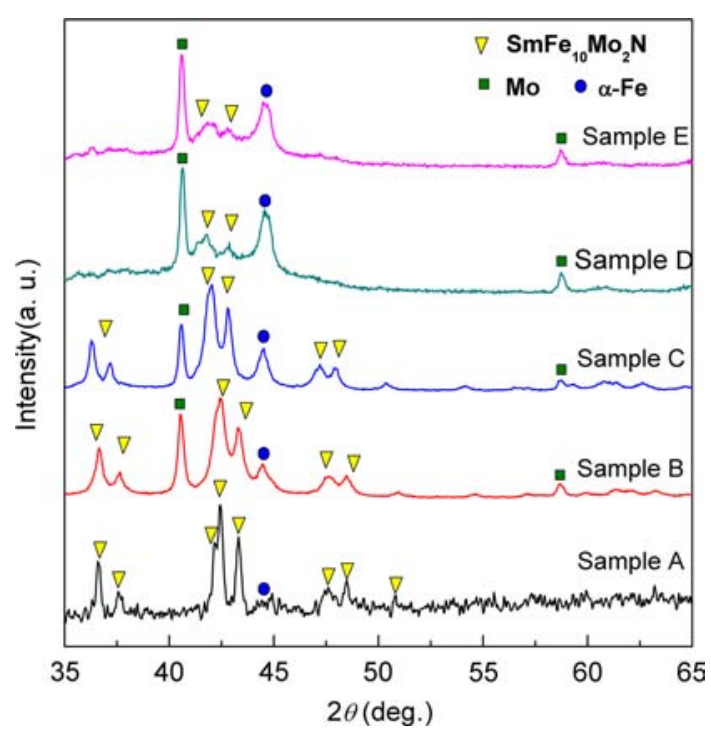

Fig. 1 XRD patterns of bulk $\mathrm{SmFe}_{10} \mathrm{Mo}_{2}$ (sample A), milled $\mathrm{SmFe}_{10} \mathrm{Mo}_{2}$ powder (sample $\mathrm{B}$ ), the nitrogenized $\mathrm{SmFe}{ }_{10} \mathrm{Mo}_{2}$ powders under $0.1 \mathrm{MPa}$ (sample C), $20 \mathrm{MPa}$ (sample D), $40 \mathrm{MPa}$ (sample E) 
Table 1 Structural data of the $\mathrm{SmFe}_{10} \mathrm{Mo}_{2}$ powder and its nitrides

\begin{tabular}{lll}
\hline Samples & $a(\AA)$ & $c(\AA)$ \\
\hline B & 8.54 & 4.784 \\
C & 8.594 & 4.914 \\
D & 8.600 & 4.929 \\
E & 8.601 & 4.931 \\
\hline
\end{tabular}

whereas for sample E, the particle size is clearly smaller with a size distribution from $4 \mu \mathrm{m}$ to $50 \mathrm{~nm}$. The decrease in particle size can be mainly ascribed to the increase in deposited $\alpha$-Fe. As it can be seen from Fig. $2 b, d, S m, F e$, Mo and $\mathrm{N}$ are detected by EDS and the $\mathrm{N}$ content increases from 22.1 at $\%$ for sample $\mathrm{C}$ to 22.9 at\% for sample $\mathrm{E}$. The results show that high-pressure nitrogenation is beneficial for increasing the $\mathrm{N}$ content as well as for decreasing the particle size.

The temperature dependence of the magnetization of $\mathrm{SmFe}_{10} \mathrm{Mo}_{2}$ and its nitrides was measured in a field of 0.05 $\mathrm{T}$ during a warming process, as shown in Fig. 3a. For the bulk sample, with increasing temperature, a magnetic phase transition from the ferromagnetic to the paramagnetic state takes place at $T_{\mathrm{C}}$, of about $543 \mathrm{~K}$, which is higher than those reported earlier [7, 17]. This can be ascribed to a slight variation of Mo concentration which can greatly influence $T_{\mathrm{C}}$ [17]. The lower $T_{\mathrm{C}}$ of $519 \mathrm{~K}$ for the as-milled sample $\mathrm{B}$ may result from the smaller particle size and precipitation of Mo. In Fig. $3 \mathrm{a}, T_{\mathrm{C}}$ is defined as the temperature corresponding to the minimum in the temperature dependence of the first derivative of the magnetization. It can be clearly seen that after nitrogenation at $0.1 \mathrm{MPa}, T_{\mathrm{C}}$ has largely increased to $633 \mathrm{~K}$. It is well known that the $\mathrm{Fe}-\mathrm{Fe}$ interaction is a key factor that influences the magnetic properties of Fe-rich rare earth iron compounds, and $T_{\mathrm{C}}$ strongly depends on the $\mathrm{Fe}-\mathrm{Fe}$ distance [18]. As mentioned above, the $\mathrm{N}$ atoms in $\mathrm{SmFe}_{10} \mathrm{Mo}_{2} \mathrm{~N}_{x}$ occupy exclusively the $2 \mathrm{~b}$ interstitial sites [7]. Therefore, the increase in $T_{\mathrm{C}}$ in the present nitrides might be attributed to the change in the $\mathrm{Fe}-\mathrm{Fe}$ bond length caused by the interstitial $\mathrm{N}$ atoms. The remarkable decrease in $T_{\mathrm{C}}$ of the samples D (417 K) and E (407 K), which have been nitrogenized at high pressure, can be ascribed to precipitation of a large amount of $\alpha$-Fe. The $\mathrm{N}$ contents in the nominal composition $\mathrm{La}_{0.5} \mathrm{Pr}_{0.5} \mathrm{Fe}_{11.4} \mathrm{Si}_{1.6} \mathrm{~N}_{x}$ for sample $\mathrm{C}$ nitrogenized at $0.1 \mathrm{MPa}$ and sample D nitrogenized at $20 \mathrm{MPa}$ were roughly evaluated by the weight difference before and after nitrogenation as $x=0.5$ and 2.1 , respectively. The $\mathrm{N}$ content of $x=0.5$ is roughly in consistent with those of $\mathrm{NdFe}_{10} \mathrm{Mo}_{2}$ [19] and $\mathrm{YTiFe}_{11}$ nitrides [20] nitrogenized at atmospheric pressure. The present result shows that nitrogenation at high pressure results in decomposition of 1:12 main phase.

The magnetic hysteresis loops of $\mathrm{SmFe}_{10} \mathrm{Mo}_{2}$ and the nitrides at room temperature, as shown in Fig. 3b, show
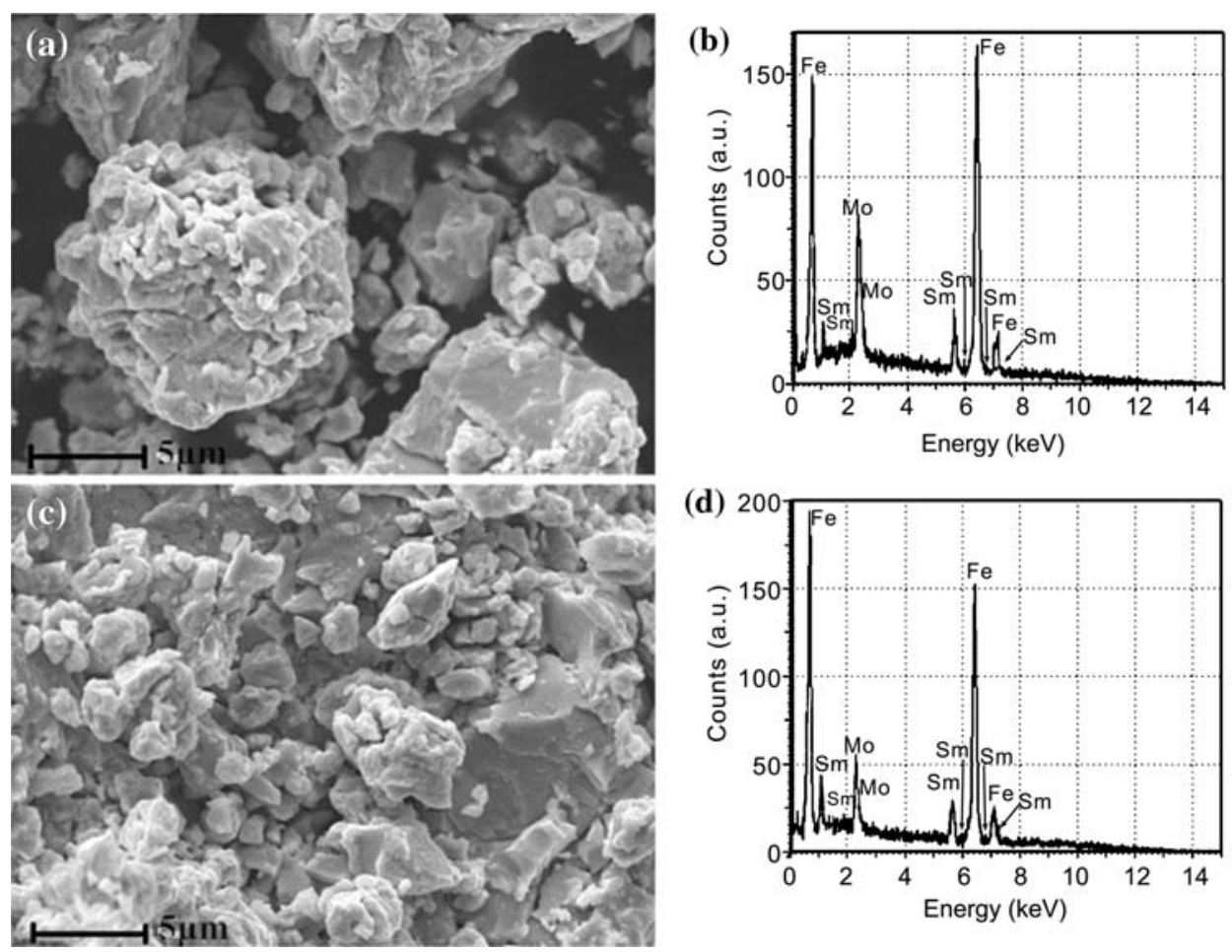

Fig. 2 SEM images and EDS results of sample C nitrogenized at $0.1 \mathrm{MPa} \mathbf{a}, \mathbf{b}$, sample E nitrogenized at $40 \mathrm{MPa} \mathbf{c}, \mathbf{d}$ 
(a)

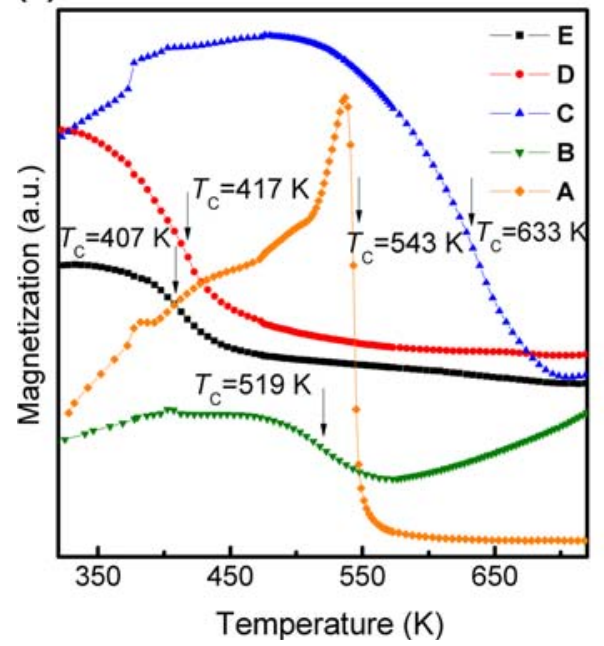

(b)

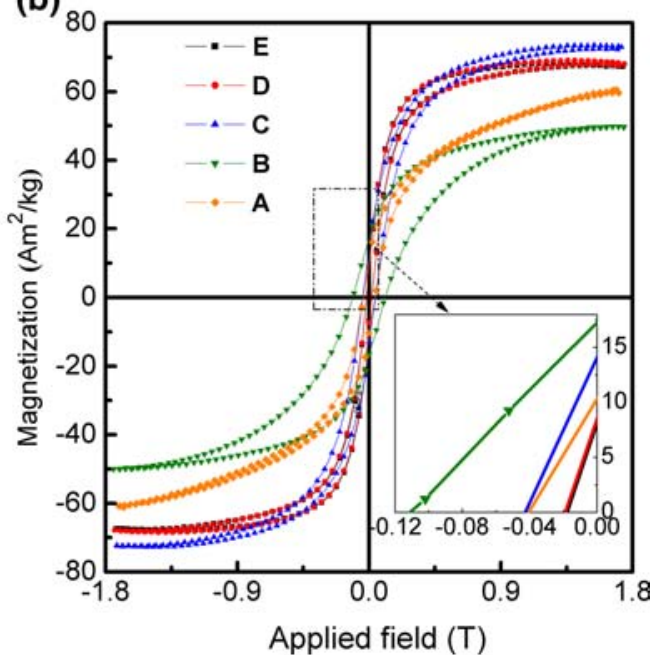

Fig. 3 Temperature dependence of the magnetization at $0.05 \mathrm{~T} \mathbf{a}$, magnetic hysteresis loop at room temperature $\mathbf{b}$ of the samples

that upon milling, the saturation magnetization $\left(M_{\mathrm{s}}\right)$ decreases from 60.3 to $50.2 \mathrm{Am}^{2} / \mathrm{kg}$, accompanied an increase in the coercivity from 0.04 to $0.12 \mathrm{~T}$. The decrease in $M_{\mathrm{s}}$ after milling may be explained by the decrease in the grain size and by the precipitation of Mo, which leads to a decrease in main phase. The increase in coercivity should originate from the smaller particle size, the large residual stress and a large density of defects, which are introduced in the ball-milling process [21-23]. As shown in the inset of Fig. 3b, upon nitrogenation, the coercivity of the sample E nitrogenized at $40 \mathrm{MPa}$, strongly decreases to $0.018 \mathrm{~T}$, which can be explained by the precipitation of soft magnetic $\alpha$-Fe. The magnetic features of the $\mathrm{SmFe}_{10} \mathrm{Mo}_{2}$ and its nitrides are listed in Table 2.

\subsection{Influence of Nitrogenation on the Microwave- \\ Absorption Properties of $\mathrm{SmFe}_{10} \mathrm{Mo}_{2}$}

In order to investigate the influence of nitrogenation on the microwave-absorption properties of $\mathrm{SmFe}_{10} \mathrm{Mo}$ and its nitrides, the frequency dependence of the real part $\left(\varepsilon^{\prime}\right)$ and the imaginary part $\left(\varepsilon^{\prime \prime}\right)$ of the relative complex permittivity of the paraffin-SmFe ${ }_{10} \mathrm{Mo}_{2}$ composites and paraffin$\mathrm{SmFe}_{10} \mathrm{Mo}_{2}$-nitride composites have been measured and are shown in Fig. 4a. It can be seen that for both samples B and $\mathrm{C}, \varepsilon^{\prime}$ shows fluctuating behavior with three peaks around 7.4, 13.2 and $17.4 \mathrm{GHz}$, which can be attributed to the interfacial polarization and the displacement current lag at the metal/insulator interface [24]. In the $\varepsilon^{\prime \prime}$ curves, four peaks at 5.5, 10.2, 14.6 and 17.6 GHz can be observed and $\varepsilon^{\prime}$ exhibits a maximum and a minimum just below and above the frequency. This phenomenon is characteristic for nonlinear dielectric resonance [25].
The imaginary part of the relative complex permittivity, $\varepsilon^{\prime \prime}$, first decreases from 0.3 to 0.1 in the $1-4 \mathrm{GHz}$ range and then fluctuates from 0.02 to 0.1 in the $4-18 \mathrm{GHz}$ range. The lower $\varepsilon^{\prime \prime}$ values of the paraffin- $\mathrm{SmFe}_{10} \mathrm{Mo}_{2}$ composites show a higher resistivity than other ferromagnetic metal-based composites, such as $\varepsilon^{\prime \prime}=48-148$ for $\mathrm{Nd}_{2} \mathrm{Fe}_{14} \mathrm{~B}$ microparticles with an average particle size of $3.4 \mu \mathrm{m} \quad[15]$, and $\varepsilon^{\prime \prime}=1.6-2.6$ for $\mathrm{Fe}(\mathrm{Mn}) /$ ferrite nanocapsules [24]. This can be ascribed to the fact that there exists an oxidation layer at the surface of the $\mathrm{SmFe}_{10} \mathrm{Mo}_{2}$ nanoparticles which prevents the $\mathrm{SmFe}{ }_{10} \mathrm{Mo}_{2}$ phase to form electrical conducting networks so that the electrical resistivity of the paraffin- $-\mathrm{SmFe}_{10} \mathrm{Mo}_{2}$ composites is increased.

Figure $4 \mathrm{~b}$ shows the real part $\left(\mu^{\prime}\right)$ and the imaginary part $\left(\mu^{\prime \prime}\right)$ of the relative complex permeability $\left(\mu_{\mathrm{r}}\right)$ of samples B and $\mathrm{C}$, for which $\mu^{\prime}$ exhibits a decrease from 1.1 and 1.0 to 0.93 and 0.84 , respectively, in the $2-4 \mathrm{GHz}$ range. With further increasing the frequency, $\mu^{\prime}$ shows fluctuating behavior with three peaks around 4.6, 10.2 and $15.8 \mathrm{GHz}$. The higher value of $\mu^{\prime}$ for the nitrogenized sample originates from the higher $M_{\mathrm{s}}$. As shown in Table 2, after nitrogenation, $M_{\mathrm{s}}$ has been increased from 50.2 to $74.1 \mathrm{Am}^{2} /$ $\mathrm{kg}$ due to further precipitation of soft magnetic $\alpha$-Fe. The imaginary part $\mu^{\prime \prime}$ exhibits two broad resonance peaks at about 6.8-8.9 and 14.3-15.9 GHz. Similar broad magnetic resonance peaks have been observed in $\mathrm{Co} / \mathrm{TiO}_{2}[26]$ and $\mathrm{Ni} / \mathrm{Al}_{2} \mathrm{O}_{3}$ [9] nanocomposites. The multi-resonance peaks, as shown in Fig. 3b, can be defined as "exchange mode" resonance and are ascribed to the small size effect, the surface effect and spin-wave excitations [24]. The resonance frequency depends on the radii of the particles. In comparison with the as-milled sample, the nitrogenized 
Table 2 Magnetic features of $\mathrm{SmFe}_{10} \mathrm{Mo}_{2}$ and its nitrides

\begin{tabular}{llll}
\hline Samples & $M_{\mathrm{s}}\left(\mathrm{Am}^{2} / \mathrm{kg}\right)$ & $H_{\mathrm{cj}}(\mathrm{T})$ & $T_{\mathrm{C}}(\mathrm{K})$ \\
\hline A & 60.3 & 0.04 & 543 \\
B & 50.2 & 0.12 & 519 \\
C & 74.1 & 0.04 & 633 \\
D & 69.1 & 0.019 & 417 \\
E & 67.8 & 0.018 & 407 \\
\hline
\end{tabular}

sample shows a lower $\mu^{\prime \prime}$ value, indicating a lower magnetic loss. This may originate from the influence of eddy currents due to the increase in particle size in the nitrogenation process. The RL value was calculated according to the transmission line theory and is shown in Fig. 5; a largest $\mathrm{RL}$ of $-5.2 \mathrm{~dB}$ is obtained for the as-milled nanoparticles at $15 \mathrm{GHz}$ for an absorber thickness of $9 \mathrm{~mm}$. The RL value is higher than the $3 \mathrm{~dB}$ for $\mathrm{Nd}_{2} \mathrm{Fe}_{14} \mathrm{~B}$ microparticles [15] but lower than the $13.2 \mathrm{~dB}$ for $\mathrm{Nd}_{2} \mathrm{Fe}_{14} \mathrm{~B} / \mathrm{C}$ paraffin mainly due to the increased dielectric loss from the enhancement of resistivity by the dielectric component $\mathrm{C}$. It is observed that the RL values do not exceed $-5 \mathrm{~dB}$ in the $2-18 \mathrm{GHz}$ range and the largest RL value is $-4 \mathrm{~dB}$ at $14.8 \mathrm{GHz}$ for the $\mathrm{SmFe}_{10} \mathrm{Mo}$ nitride nanoparticles. The decrease in microwave absorption effect after nitrogenation can be mainly ascribed to the lower magnetic loss. The frequency corresponding to the largest $\mathrm{RL}$ is consistent with the frequencies of the magnetic

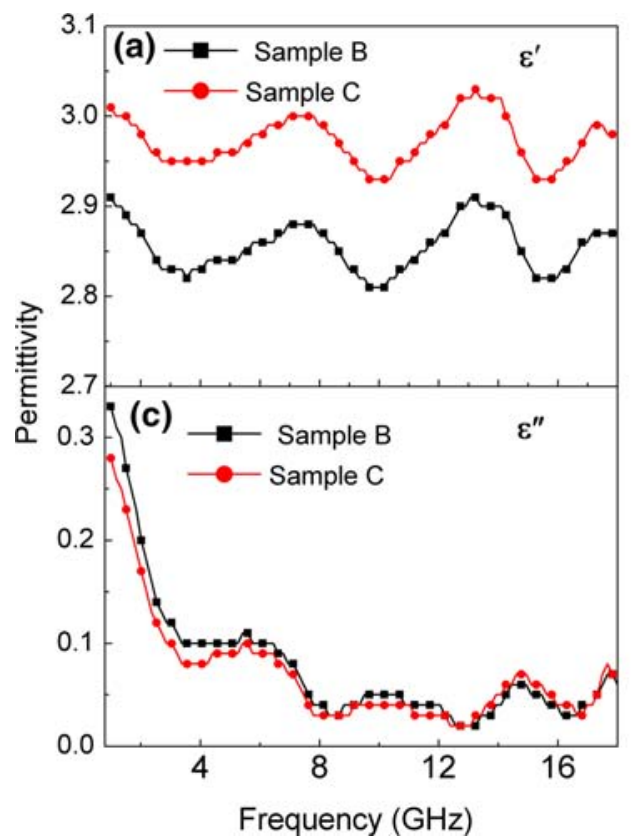

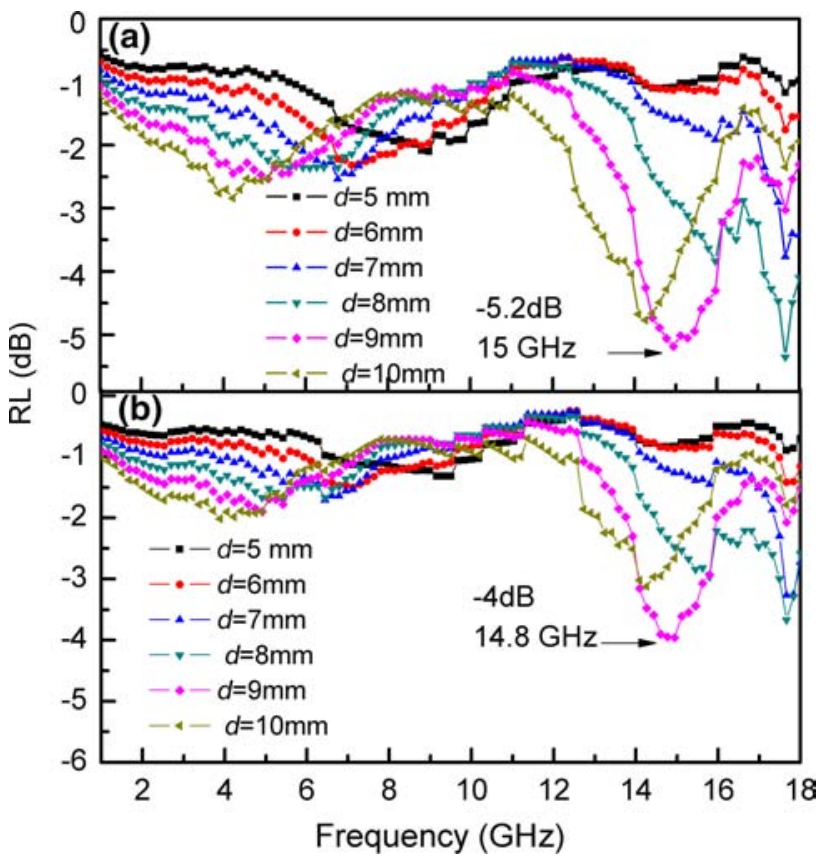

Fig. 5 Frequency dependence of the reflection loss of sample A a, sample $\mathbf{C}$ b dispersed in paraffin

resonance and the dielectric resonance, as shown in Fig. 4, showing that the main microwave absorption originates from a combined effect of magnetic and dielectric loss.

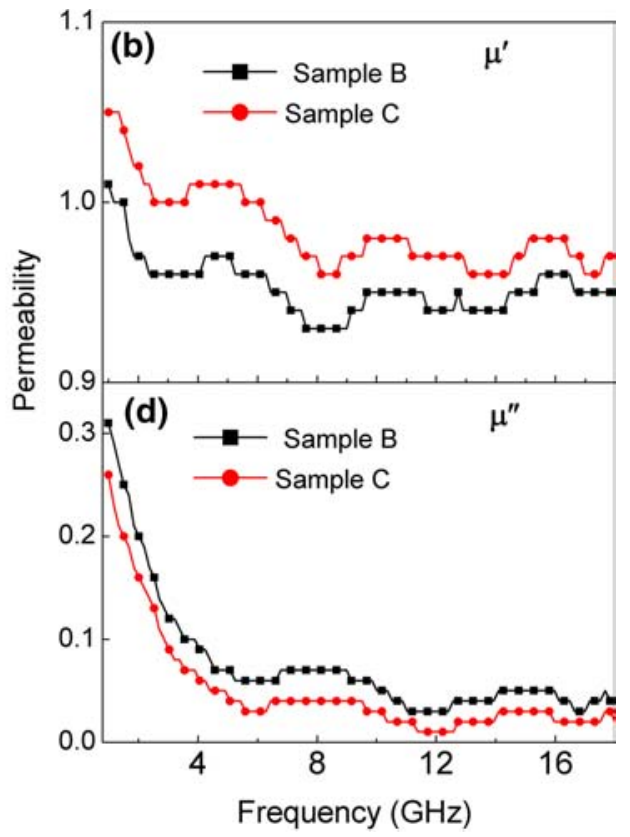

Fig. 4 Frequency dependence of the relative permittivity a, $\mathbf{c}$, the relative permeability $\mathbf{b}, \mathbf{d}$ of $\mathrm{SmFe}_{10} \mathrm{Mo}_{2}$ and its nitride dispersed in paraffin 


\section{Conclusions}

Upon nitrogenation at atmospheric pressure, the lattice parameters, $a$ and $c$, of $\mathrm{SmFe}_{10} \mathrm{Mo}_{2}$ show a large increase by $0.5 \%$ and $2.7 \%$, respectively, and the Curie temperature $T_{\mathrm{C}}$ strongly increases from 519 to $633 \mathrm{~K}$. High-pressure nitrogenation at $40 \mathrm{MPa}$ leads to decomposition of the 1:12 main phase, as a result of which $T_{\mathrm{C}}$ strongly decreases to $407 \mathrm{~K}$, accompanying a decrease in the coercivity to 0.018 $\mathrm{T}$. The largest RL of $-5.2 \mathrm{~dB}$ is obtained for the as-milled nanoparticles at $15 \mathrm{GHz}$ for an absorber thickness of $9 \mathrm{~mm}$. After nitrogenation, the microwave absorption effect decreases mainly due to the decrease in magnetic loss, which may originate from the influence of eddy currents.

Acknowledgments This work was financially supported by the National Natural Science Foundation of China (No. 51261001), Liaoning Provincial Natural Science Foundation (No. 2013020105) and Shenyang Science and Technology Foundation (No. F13-316-139).

\section{References}

[1] J.M.D. Coey, H. Sun, J. Magn. Magn. Mater. 87, L251 (1990)

[2] Y.Z. Wang, G.C. Hadjipanayis, J. Appl. Phys. 70, 6009 (1991)

[3] J. Yang, S.Z. Dong, Y.C. Yang, B.P. Cheng, J. Appl. Phys. 75, 3013 (1994)

[4] O. Isnard, M. Guillot, J. Appl. Phys. 85, 4681 (1999)

[5] Y.C. Yang, Z.X. Liu, X.D. Zhang, B.P. Cheng, S.L. Ge, J. Appl. Phys. 76, 1745 (1994)

[6] Q. Pan, X.D. Zhang, B.P. Cheng, Y.C. Yang, J. Appl. Phys. 75, 5441 (1994)

[7] V. Psycharis, M. Anagnostou, C. Christides, D. Niarchos, J. Appl. Phys. 70, 6122 (1991)

[8] Z.G. Xie, D.Y. Geng, X.G. Liu, S. Ma, Z.D. Zhang, J. Mater. Sci. Technol. 27, 607 (2011)
[9] S.N. Xu, M.X. Zhao, Z.Q. Cai, N.K. Sun, F. Liu, B.S. Du, X.Y. Zhang, Z.J. Ling, Acta Metall. Sin. (Engl. Lett.) 26, 385 (2013)

[10] H. Wang, H.H. Guo, Y.Y. Dai, D.Y. Geng, Z. Han, D. Li, T. Yang, S. Ma, W. Liu, Z.D. Zhang, Appl. Phys. Lett. 101, 173117 (2012)

[11] J.H. He, W. Wang, A.M. Wang, J.G. Guan, Acta Metall. Sin. (Engl. Lett.) 25, 201 (2012)

[12] V. Revathi, S.D. Kumar, P.C. Lekha, V. Subramanian, T.S. Natarajan, C. Muthamizhchelvan, Acta Metall. Sin. 27, 557 (2014)

[13] N.K. Sun, B.S. Du, F. Liu, P.Z. Si, M.X. Zhao, X.Y. Zhang, G.M. Shi, J. Alloys Compd. 577, 533 (2013)

[14] Q. Zhang, C.F. Li, Y.N. Chen, Z. Han, H. Wang, Z.J. Wang, D.Y. Geng, W. Liu, Z.D. Zhang, Appl. Phys. Lett. 97, 133115 (2010)

[15] X.G. Liu, S.W. Or, S.L. Ho, D.Y. Geng, Z.G. Xie, H. Wang, Z.D. Zhang, J. Alloys Compd. 509, 2929 (2009)

[16] S.L. Tang, C.H. Wu, X.M. Jin, B.W. Wang, G.S. Li, B.Z. Ding, Y.C. Chuang, J. Alloys Compd. 264, 240 (1998)

[17] X.C. Kou, E.H.C.P. Sinnecker, R. Grössinger, G. Wiesinger, T. Zhao, J.P. Liu, F.R. de Boer, J. Magn. Magn. Mater. 140-144, 1025 (1995)

[18] J.L. Zhao, J. Shen, F.X. Hu, Y.X. Li, J.J. Sun, B.G. Shen, J. Appl. Phys. 107, 113911 (2010)

[19] Y.Z. Wang, G.C. Hadjipanayis, Z.X. Tang, W.B. Yelon, V. Papaefthymiou, A. Moukarika, D.J. Sellmyer, J. Magn. Magn. Mater. 119, 41 (1990)

[20] Y.C. Yang, X.D. Zhang, L.S. Kong, Q. Pan, S.L. Ge, J.L. Yang, Y.F. Ding, B.S. Zhang, C.T. Ye, L. Jin, Solid State Commun. 78, 313 (1991)

[21] G. Herzer, W. Fernengel, E. Adler, J. Magn. Magn. Mater. 58, 48 (1986)

[22] Q. Zeng, I. Baker, V. McCreary, Z.C. Yan, J. Magn. Magn. Mater. 318, 28 (2007)

[23] N.K. Sun, F. Liu, Y.B. Gao, Z.Q. Cai, B.S. Du, S.N. Xu, P.Z. Si, Appl. Phys. Lett. 100, 112407 (2012)

[24] Z. Han, D. Li, X.G. Liu, D.Y. Geng, J. Li, Z.D. Zhang, J. Phys. D 42, 055008 (2009)

[25] X.G. Liu, S.W. Or, S.L. Ho, D.Y. Geng, Z.G. Xie, H. Wang, Z.D. Zhang, J. Alloys Compd. 509, 2929 (2011)

[26] X. Ni, J. Ma, J.G. Li, D.M. Jiao, J.J. Huang, X.D. Zhang, J. Alloys Compd. 468, 368 (2009) 